\title{
Construction and Practice of SPOC Teaching Mode based on MOOC
}

\author{
https://doi.org/10.3991/ijet.v13i12.9702
}

Zhe Kang $(\bowtie)$

Beijing Foreign Studies University, Beijing, China

kangzhe@bfsu.edu.cn

Le $\mathrm{He}$

Université du Québec à Trois-Rivières, Trois-Rivières, Canada

\begin{abstract}
Traditional teaching focuses on teachers' instructions. However, it provides few opportunities for teacher-student interaction. The use of this single teaching form impedes the independent learning ability of students. In contrast, the massive open online course (MOOC) teaching mode completely depends on independent student learning, but it lacks effective monitoring. Thus, the MOOC approach results in low course completion rates and fails to completely replace the traditional classroom teaching model. This study constructed a teaching mode called a small private online course (SPOC) by combining MOOC and traditional teaching modes to increase the teaching effect. The specific application process of the SPOC teaching mode was illustrated using the case study of "College English." The study showed that the SPOC teaching mode has more extensive teaching content, promotes stronger learning interest in students, and offers better teacher-student interaction than the traditional teaching mode. Moreover, the SPOC teaching mode improved the independent learning ability of students, addressed the shortcomings of traditional classroom teaching, and facilitated deep application of information technology in classroom teaching.
\end{abstract}

Keywords-MOOC, SPOC, teaching mode

\section{Introduction}

The integration of education and information technology has improved with the development of technology and the popularization of the Internet. This development has affected the traditional teaching mode and learning. The constraints of geographical factors or learning communities on knowledge propagation has continuously decreased in the digital era. The emergence of open online courses is bringing unprecedented progresses in knowledge propagation and sharing. As a result, massive open online courses (MOOCs) have been highly appreciated by the public since their development. MOOCs aim to "transmit the best education resources in the world to the most remote places on earth."[1] MOOC has created a new tide of learning and knowledge construction. The characteristics of MOOC, which include "large scale," 
"open," and "online," can meet the people's pursuit for knowledge. However, the disadvantages of MOOC have also become increasingly evident. Without effective supervision, few learners complete MOOCs. Some students do not accept MOOCs due to different cultural backgrounds and education methods. Moreover, the lack of traditional links, such as face-to-face communication with tutors/teachers, prevents some students from deepening their study in MOOCs. As a result, MOOCs offer insignificant contributions to traditional college education. In 2013, Professor Armando Fox proposed small private online courses (SPOCs) for the first time [2]. He expected to apply online courses into actual small-scaled teaching classroom activities by combining high-quality MOOC resources and face-to-face classroom teaching.

The SPOC teaching mode, based on MOOCs, combines the current education mode and information technology. SPOCs offset the shortcomings of traditional college education to some extent and bring teachers and students into a more open, sharing, fair, and interactive space. SPOCs create an emerging teaching mode that emphasizes the leading role of students and assisting role of teachers. However, the implementation and application of SPOCs in classroom teaching is a problem that has yet to be investigated and/or resolved.

\section{State of the art}

In traditional the teaching mode, teachers occupy the central role and explain knowledge from textbooks while students passively accept knowledge and instructions from the teachers. The performance of teachers in the classroom is restricted. Thus, they do not accurately address the learning progress of students. Moreover, the limited classroom teaching time hinders students' deep exploration of knowledge, which causes the large gap between learned knowledge and their knowledge demands.[3] MOOC is similar to a virtual school that possesses a high-quality resource platform, famous teacher courses, and almost zero-cost open accession. MOOCs meet knowledge pursuit of all communities and stimulate people's hopes for first-class teachers, high-quality courses, education reform, and education fairness.[4] However, the characteristics of open online teaching, lack of face-to-face communication, and complete absence of teaching experiences cause low completion and high dropout rates [5].

Professor Fox believed that universities initially created MOOCs as a form of teaching assistance [6] and contended that teaching staff had not realized the true value of MOOCs. The proposition of SPOC is to combine MOOCs and traditional teaching to improve education services for large-scaled communities as the extension of MOOCs [7]. Professor Agarwal, from the Massachusetts Institute of Technology, considered SPOCs as a branch of MOOCs with a teaching direction applicable to small-scaled communities produced from the current development of MOOCs [8]. Hoffmann believed that SPOCs were the organic combination of MOOCs and classroom teaching because they are a mixed teaching mode of in-class and online teaching.[9] Professor Lue from Harvard University indicated that the importance of SPOCs was to help online learning that attempts to imitate current classroom courses 
and to create flexible and effective activities [10]. These studies mainly focused on the connotation and effects of SPOC and instruction of teaching before the courses. They focused on the step of knowledge acceptance but did not represent the role and value of SPOCs for deep learning, such as classroom communication and after-class practices.

The current study thoroughly introduced the construction of an SPOC teaching mode based on MOOCs because theoretical studies are abundant but practical explorations of SPOC, including early applications and late descriptions, are limited. The associated implementation and application problems of the SPOC teaching model were comprehensively analyzed by a case study of "College English." The teaching effect of the SPOC was explored through a questionnaire and interviews from a practical perspective.

The remainder of this study is organized as follows. Section 3 introduces the definitions, characteristics, and differences of MOOCs and SPOCs. Section 4 describes the construction of an SPOC teaching mode applicable to a university campus by combining MOOCs and traditional teaching. Section 5 evaluates classroom practice and the teaching effect of the SPOC teaching mode. Section 6 presents the conclusion.

\section{SPOC teaching mode based on MOOC}

\subsection{Characteristics of MOOC}

Dave Cormier and Bryan Alexander from Canada proposed MOOCs in 2008.[11] MOOCs can be defined as the public-oriented large open online course launched with Internet development. In 2011, Stanford University constructed a MOOC on "Machine Learning" and released it on the internet for free. More than 100,000 people around the world registered for this course. In 2012, three MOOC giants, namely, Coursera, Udacity, and edX, were developed. They attracted many university professors and scholars to release MOOCs. The New York Times called 2012 the "First Year of MOOC" [12]. MOOCs have developed rapidly since then.

MOOCs have distinguishing features from the traditional teaching mode.

1. Elective: MOOCs provide abundant high-quality resources (Fig. 1). Appropriate MOOCs can be selected by students according to their interests or needs. The openness of MOOCs guarantees knowledge propagation. The MOOC platform is conducive to students who want to learn knowledge to gain maximum achievement in the most economical way.

2. Autonomy: In Fig. 2, learning time and place can be freely selected according to the situation. Students can learn whenever and wherever possible. Moreover, the learning content, learning schedule, watch times of the videos, and the play speed of videos can be flexibly set according to their situations. Thus, they can truly realize learning on demand. MOOCs solve students' problems with fragmented time management and allow learning independence and the positivity of students to some extent. 
3. Interaction: Unlike previous single online courses, MOOCs not only provide famous teachers but also set up a high-quality online platform to provide great opportunities for learners to participate in communication and interaction. Students learn knowledge online, take exams on the platform, and receive feedback. They can also communicate difficulties and questions in the learning community. Students can interact with teachers and other students through the platform whenever and wherever. Fig. 3 shows the interaction relationship. However, the interaction rate is low and results in a poor effect, which is attributed to the large student population, limited energy of the teachers, and the large gap in student levels.

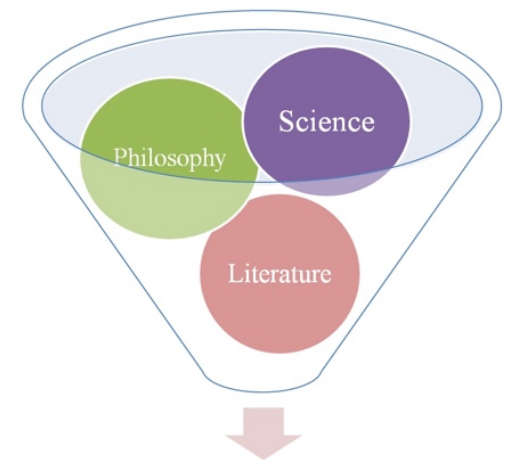

Elective

Fig. 1. Elective relationship of MOOC

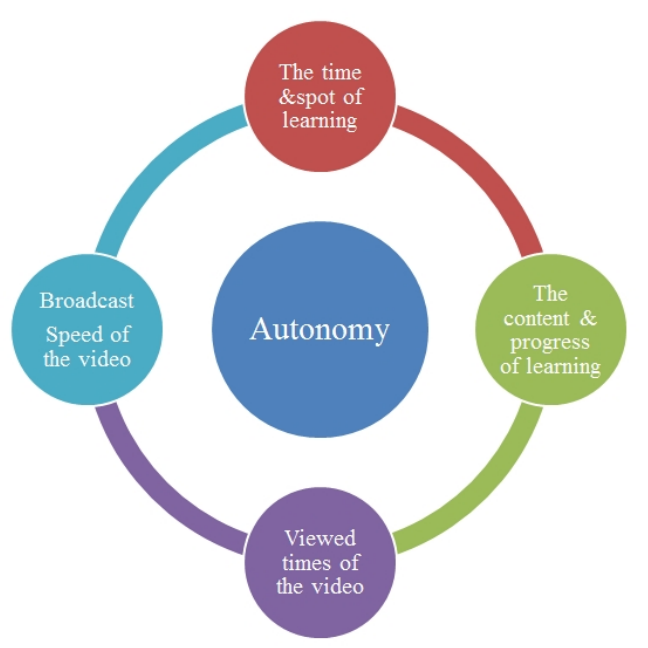

Fig. 2. Autonomy relationship of MOOC 


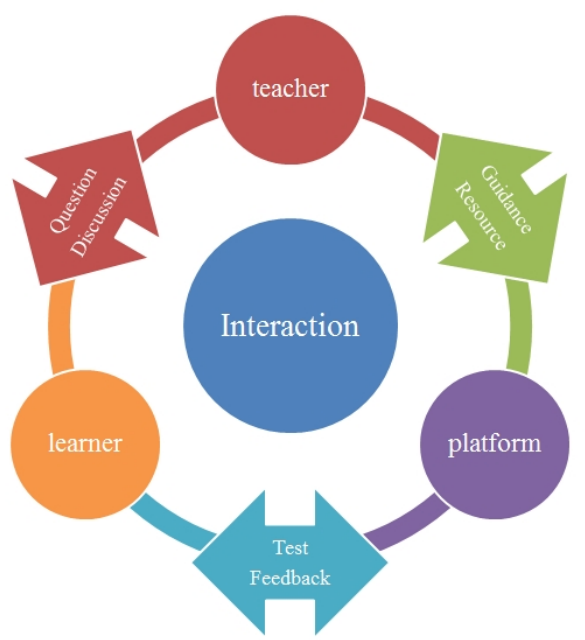

Fig. 3. Interaction relationship of MOOC

\subsection{SPOC: The post-MOOC era}

SPOCs are derived from MOOCs. SPOCs are open online courses applicable to a small community by combining MOOCs and classroom teaching. Thus, SPOCs can be considered a MOOC with a fixed number of members [13]. On this basis, SPOCs avoid many shortages of MOOCs caused by large-scale and open characteristics. Small and private SPOCs are relative in size to massive and open MOOCs. "Small" refers to the limited number of students, which generally ranges between dozens and hundreds. This phenomenon is conducive to teachers identifying the learning abilities of the students, promoting teaching interactions, and improving the participation of students. "Private" means that the course is only open to a small number of applicants who meet to the accession standards to secure privacy. Students have a sense of responsibility for the limited resources, thereby increasing their attention and learning. These phenomena assure the learning quality and enthusiasm of the students. A comparison of MOOCs' and SPOCs' "philosophies," "resources," and "management modes" is shown in Table 1. Discourse transfer from MOOCs to SPOCs also reflects that people's cognition and expectation to MOOC are becoming increasingly reasonable.

Table 1. Comparison between MOOC and SPOC

\begin{tabular}{|l|l|l|}
\hline & \multicolumn{1}{|c|}{ MOOC } & \multicolumn{1}{|c|}{ SPOC } \\
\hline Philosophy & $\begin{array}{l}\text { MOOC emphasizes openness and advocates for } \\
\text { "open teaching." It has no restrictions to the } \\
\text { knowledge basis and professional conditions of } \\
\text { members and adopts the teaching idea of } \\
\text { "providing education for all people without } \\
\text { discrimination." }\end{array}$ & $\begin{array}{l}\text { SPOC emphasizes the "applicability" of } \\
\text { content. It pays attentions to the applica- } \\
\text { bility of the course content to registered } \\
\text { students during course selection. It } \\
\text { believes "quality prior to quantity" and } \\
\text { will reject the registration of students } \\
\text { who not qualified. }\end{array}$ \\
\hline
\end{tabular}




\begin{tabular}{|l|l|l|}
\hline $\begin{array}{l}\text { Learning } \\
\text { resources }\end{array}$ & $\begin{array}{l}\text { Teaching video is the main teaching activity of } \\
\text { MOOCs, supported with micro-video organiza- } \\
\text { tion teaching. It possesses rich learning re- } \\
\text { sources and can adapt to various types and at } \\
\text { different levels of students. }\end{array}$ & $\begin{array}{l}\text { SPOCs' teaching activities orient stu- } \\
\text { dents and only use MOOC videos. Too } \\
\text { easy or difficult micro-video resources } \\
\text { are abandoned, resulting in strong adap- } \\
\text { tation and purposeful teaching. }\end{array}$ \\
\hline $\begin{array}{l}\text { Management } \\
\text { mode }\end{array}$ & $\begin{array}{l}\text { In the MOOC teaching process, students sign in } \\
\text { "anonymously" and no restraint is set in the } \\
\text { learning process of the members. It emphasizes } \\
\text { the independent learning of students and en- } \\
\text { courages them to engage in independent and } \\
\text { free-collaborative learning. }\end{array}$ & $\begin{array}{l}\text { In the SPOC teaching process, students } \\
\text { have to register using their real names. } \\
\text { Teachers can observe the learning and } \\
\text { exam performance of students and un- } \\
\text { derstand students' learning levels } \\
\text { through the SPOC platform. }\end{array}$ \\
\hline
\end{tabular}

\subsection{Construction of SPOC teaching mode based on MOOC}

According to Combefis [14] and XuXiaoshu et al.'s [15] study on traditional routes of SPOCs as well as the SPOC pilot teaching model on "Cloud Computing and Software Engineering" in University of California - Berkeley, the construction of an SPOC teaching mode can be divided into three processes, namely, cognition (before class), internalization (during class), and increase (after class). These three processes can be further divided into three key teaching parts. In the cognition process, students sign in the online learning platform and watch the teaching videos according to the teachers' requirements or learning list. They learn independently and accomplish the after-class test according to the material content. This process is known as knowledge cognition before class. In class, students communicate and interact with their teachers and classmates about their learning problems, have group discussions, or display learning artifacts to absorb the learned knowledge. After class or in the increase process, students further explore knowledge through after-class studies or practice by applying the learned knowledge into real-life situations and correct their understanding of core knowledge to realize the sublimation of knowledge.

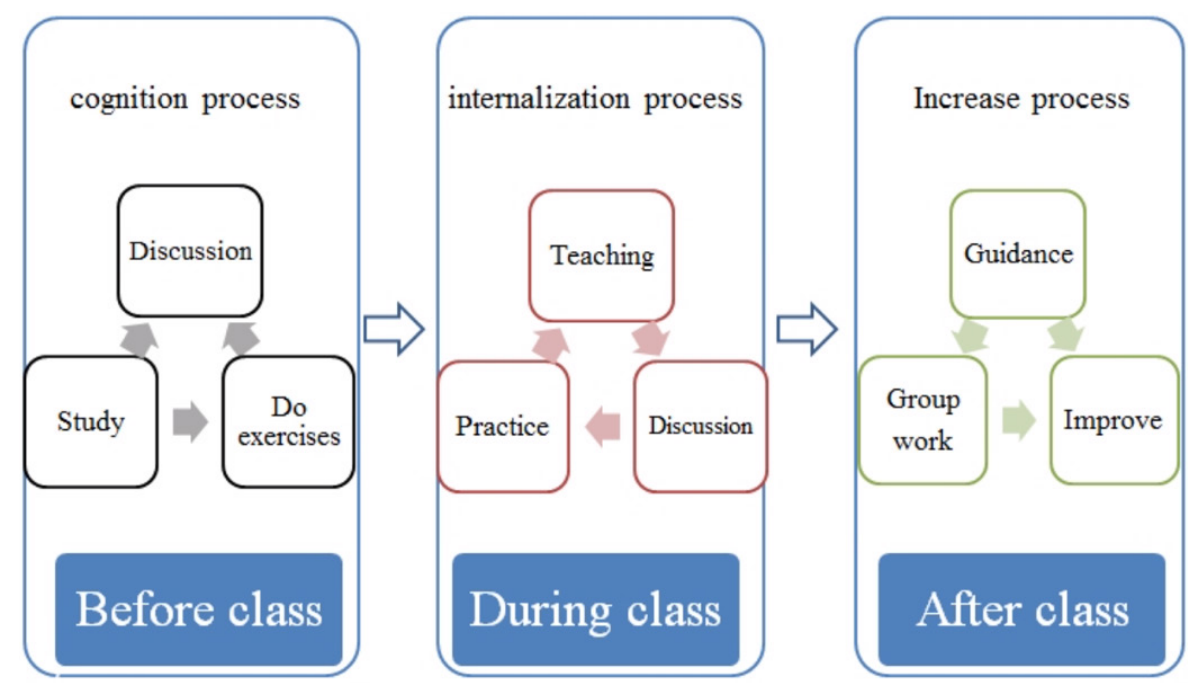

Fig. 4. SPOC teaching mode based on MOOC 
Before class: Online independent learning. In this process, the teachers control the teaching content and schedule. Centered on the MOOC content, the teachers shall arrange the texts and tasks and design examinations according to the learning situations of the students. In addition, they pay attention to online responses throughout the application of courses and offer feedback to students through online exams.

As the real executer of the SPOC teaching mode, students sign into the learning interface according to the teachers' requirements, learn the provided content in their learning time, and accomplish after-class testing and online communication activities. The process of students' participation in the SPOC teaching mode is shown in Fig. 5.

During class: Centered at classroom teaching, communication, and realizing knowledge internalization. Students master the knowledge by learning and testing on the SPOC platform before the class to identify specific problems. During class, students communicate with their teachers and classmates about these problems and practice to internalize the knowledge and increase the quality of their learning. In the "Discussion in the class," component instead of standing at a rostrum and teaching, teachers stand among students to discuss their learning situations and answer their questions. This approach helps students understand and master new knowledge. This process is shown in Fig. 6. Students acquire knowledge directly, and teachers pay attention to students' performance and knowledge acquisition.

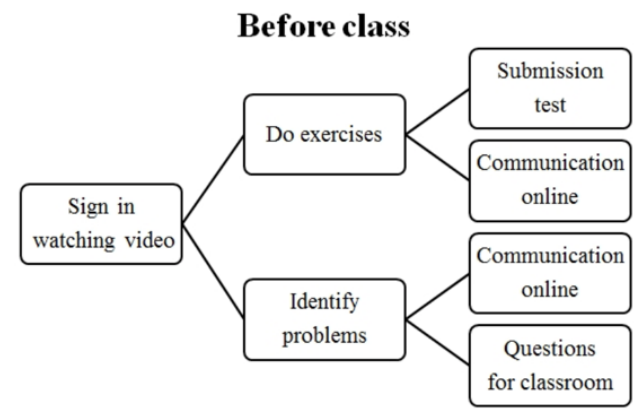

Fig. 5. Procedure of before class

\section{During class}

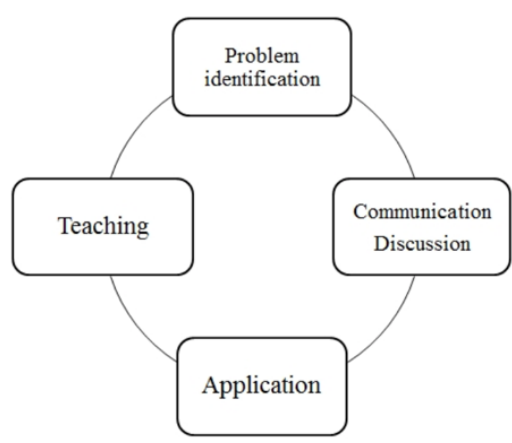

Fig. 6. Procedure during the class 
After class: Supplemented by after-class practices, sublimation of knowledge, and group cooperation. Students can implement practice innovations after the class to further consolidate and digest learned content based on course learning or expanded knowledge provided by teachers on the SPOC platform. Moreover, students can positively conduct group activities, apply knowledge to practical living situations, improve and perfect cognition of knowledge, and realize sublimation of knowledge. The "After class" process is shown in Fig. 7.

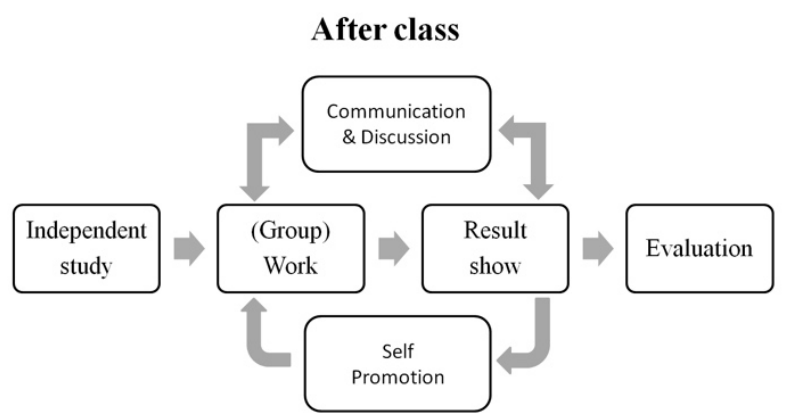

Fig. 7. Procedure of after class process

\section{Case study}

\subsection{Selection of course and research objects}

Curriculum design and teaching effect analysis were conducted on the "College English" SPOC. "College English" is a professional fundamental non-small language course for undergraduate education in China. The duration of the course is 2 academic years. In the traditional teaching mode, the teachers explain the material to the students, assisted by audio and PPT. Final examination is given to students each semester to test their learning outcomes.

The case study was implemented to students admitted in 2016 and majored in economics at the International Economy and Trade Department, Beijing Foreign Studies University of China. A total of 76 students were selected and evenly divided into two classes, 38 students in each. Class 1 was offered with SPOC teaching mode of "College English," whereas Class 2 was taught through traditional classroom teaching. Students in the two classes had similar English levels. Both classes were taught by the same teacher.

\subsection{Setting of two teaching modes}

Teaching "College English" with the SPOC occurred in the first semester of the second academic year. In the beginning, the teacher constructed the SPOC content 
with references to the MOOCs for Comprehensive College English Courses from the National University of Defense Technology and the College English Intensive Reading text (Shanghai Foreign Language Education Press) edited by Dong Yafeng. SPOC teaching content covered 14 units (Table 2), and each unit was composed of three lectures: (1) Active Reading 1 and (2) Active Reading 2: Micro-videos about text reading, article analysis, sentence pattern explanations, vocabulary learning, language characteristics, and figures of speech. Active Reading emphasized comprehensive language skills and improvement of cultural awareness. (3) Writing: emphasized development of writing skills.

Table 2. SPOC teaching contents in the first semester of 2017

\begin{tabular}{|c|c|}
\hline Course & Content \\
\hline College English & $\begin{array}{ll}\text { Unit } 1 & \text { College culture } \\
\text { Unit } 2 & \text { Mixed feelings } \\
\text { Unit } 3 & \text { Crime watch } \\
\text { Unit } 4 & \text { News } 24 / 7 \\
\text { Unit } 5 & \text { The world at war } \\
\text { Unit } 6 & \text { Sporting life } \\
\text { Unit } 7 & \text { Animal planet } \\
\text { Unit } 8 & \text { Time off } \\
\text { Unit 9 } & \text { Have you got what it takes? } \\
\text { Unit 10 } & \text { Science fact or science fiction? } \\
\text { Unit 11 } & \text { Art for Art's Sake } \\
\text { Unit 12 } & \text { Changing times } \\
\text { Unit 13 } & \text { Streets full of heroes } \\
\text { Unit 14 } & \text { Tales of Ancient and Modern }\end{array}$ \\
\hline
\end{tabular}

The SPOC on "College English" was carried out through classroom teaching every Thursday. Students logged into the teaching platform of the Digital Course of Beijing Foreign Studies University with their student ID through their cell phone or computer before Thursday and selected "English College." Applications of the SPOC teaching mode in the fifth lecture on "The world at war," as part of "English College," were introduced in the text.

The traditional classroom teaching was carried out every Tuesday. Before class, students were asked to preview the current learning content in the textbook. During class, the teacher explained the content, knowledge points, and key sentence patterns. After class, the teacher assigned written homework, and students had to complete and submit it before the next class.

\subsection{Curriculum design}

In the following section, the applications of the SPOC and the traditional teaching mode in unit 5 of "English College" are introduced.

\section{SPOC teaching mode}

Before class. Students examined the tasks from the "Curriculum Notice" and examined the content that had to be mastered in "UNIT 5 The world at war." Later, they entered the "Learning Module," which includes "Active Reading 1- Catch-22," "Active Reading 2- The story of Anne Frank's Diary," and "Writing: Description in writ- 
ing." They could learn from the micro-videos and electronic courseware one by one. Students completed in-class tests and homework in the "Class Exercises" module. Similarly, students could conduct online discussion on the learned content or difficulties in the "Class Discussion" module (Fig. 8).

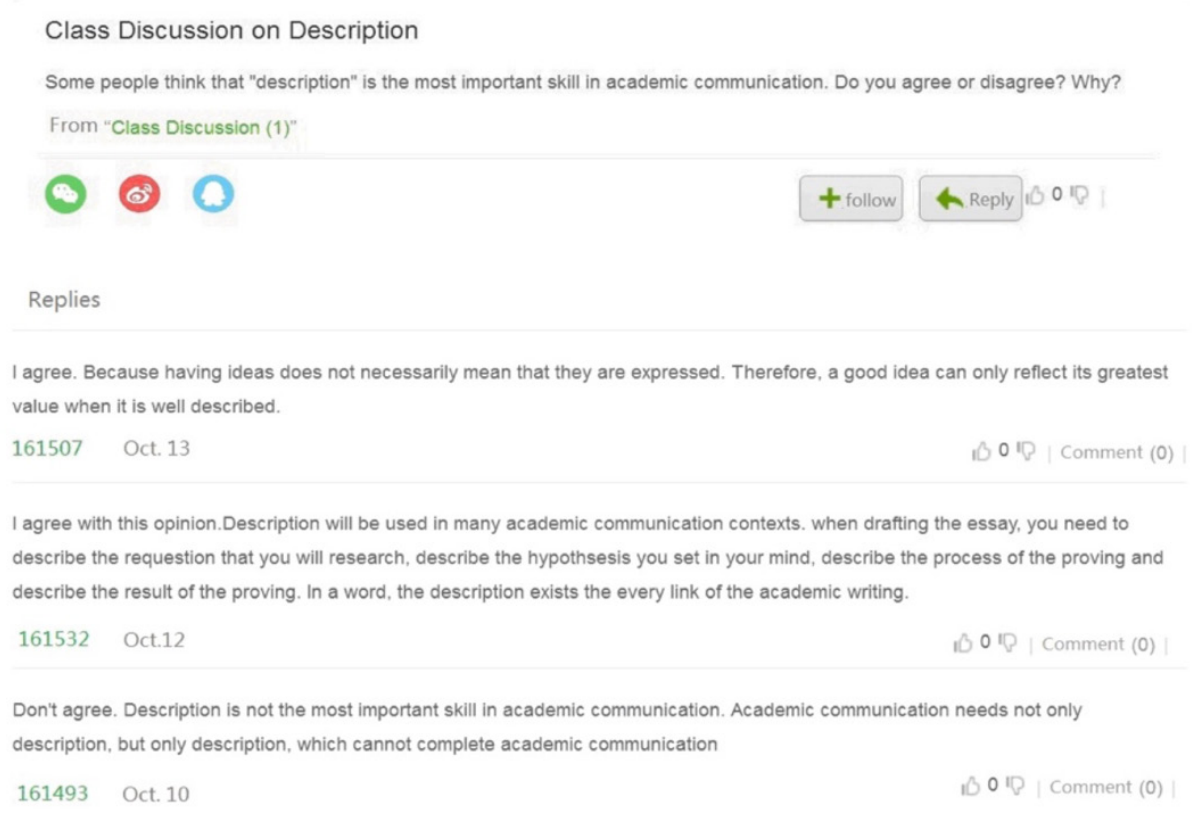

Fig. 8. Online discussion

During the class. In the SPOC teaching mode, 2 credit hours (45 minutes each) of classroom learning of "College English" were given every Thursday. Students and the teacher discussed knowledge points and problems, while the teacher explained the homework and replied to the students' questions. The class was approximately 1 hour. In the second hour, students were organized into different groups about "War and Peace," and spent 3 minutes discussing their opinions on this topic according to the curriculum content. The teacher provided instruction during the discussion to deepen the students' understanding of the material.

After class. A total of six learning groups (6-8 students in each group) were organized to discuss the topic of "Modern War." Group members selected online or faceto-face communication on the topic by collecting data from the Internet or library, displayed research conclusions through PPT or micro-videos, and finally uploaded their artifacts onto the platform. The teacher could check students' homework through the platform and provide online assistance or face-to-face instructions to the students.

Traditional teaching mode. The students previewed "UNIT 5 The world at war" according to the curriculum arrangement and marked difficulties as well as new vocabularies. During class, the teacher played the recorded text of "The world at war," introduced the background of the text, and analyzed the content and key sentence 
patterns. After the class, the teacher assigned homework to students, and the students were asked to submit it before the next class.

\subsection{Data analysis}

All research participants were tested before and after the curriculum. The academic performance of all students in these two tests was used as an evaluation of the curriculum's value. Statistical data analysis was implemented using SPSS 17.0. Inter-group differences were analyzed by one-way ANOVA and Duncan multiple comparisons. A questionnaire was distributed to all students at the end of the semester. Students were asked to answer the items to determine their attitude toward the teaching modes and opinions about the curriculum implementation. A statistical analysis of the questionnaire data was carried out using SPSS 17.0. The reliability of the questionnaire was verified by the coefficient Cronbach's $\alpha$.

\section{$5 \quad$ Teaching effect}

\subsection{Test results before and after the class}

All students were tested before and after the teaching of unit 5 for a comparison of the teaching effects of the SPOC and the traditional teaching modes. The academic performance of all students in these two tests was used as an evaluation mean of the curriculum's value. According to the test results (Table 3), no significant difference was observed between the two classes in terms of their understanding of Unit 5. At the end of the semester, a uniform test was given to the two classes according to the classroom teaching performance. Test results (Table 3) showed that given the same teacher, classroom environment, and professional structure, Class 1 (the SPOC teaching mode) achieved significantly higher mean score than Class 2 (the traditional teaching mode).

Table 3. Results of the two tests in Wechat Group and Control Group $(\mathrm{P}<0.01)$

\begin{tabular}{|l|c|c|c|}
\hline \multicolumn{1}{|c|}{ Group } & Number of samples & Average pre-test score & Average post-test score \\
\hline Class 1 & 38 & $74.25 \pm 2.45 \mathrm{~A}$ & $83.82 \pm 2.01 \mathrm{~A}$ \\
\hline Class 2 & 38 & $73.75 \pm 1.98 \mathrm{~A}$ & $76.43 \pm 1.89 \mathrm{~B}$ \\
\hline
\end{tabular}

\subsection{Questionnaire survey results}

At the end of the semester, a questionnaire was distributed and students were asked to answer honestly to determine the students' attitude toward the teaching modes and their opinions of the curriculum implementation. All 76 students participated in the survey. The main questionnaire content are listed in Table 4. 
Table 4. Questions on learners' attitudes to the current teaching mode

\begin{tabular}{|l|}
\hline \multicolumn{1}{|c|}{ Questions } \\
\hline Are you satisfied with the current teaching mode? \\
\hline Are you satisfied with your ability of master knowledge points? \\
\hline Are you satisfied with the current classroom interaction? \\
\hline Are you interested in the curriculum learning in the learning process? \\
\hline Do you improve your independent learning in the learning process? \\
\hline
\end{tabular}

A total of 76 questionnaires were collected, and statistical analysis on questionnaire data was carried out using SPSS 17.0. Internal reliability was tested by the coefficient Cronbach's $\alpha$, and the scale reliability reached $0.874(>0.7)$. The results indicate the structure and high data reliability of the questionnaire.

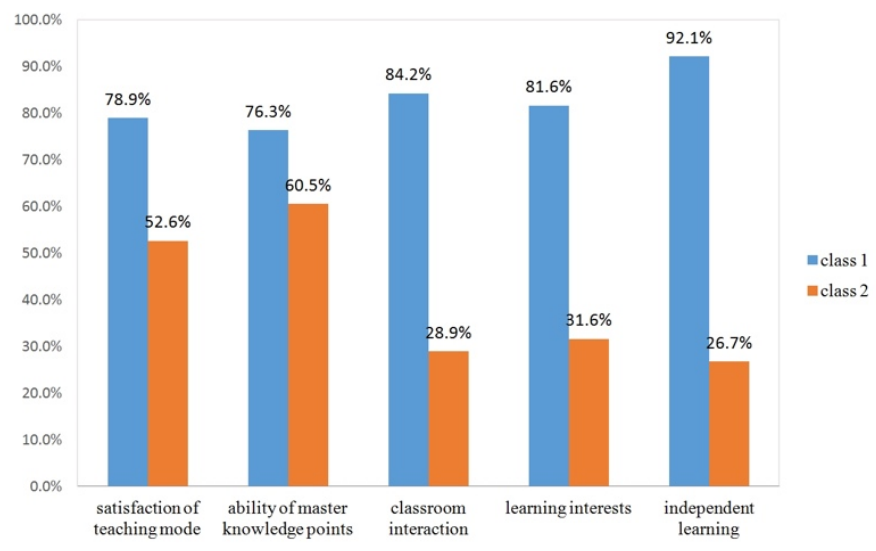

Fig. 9. Questionnaire survey results

Fig. 9 shows that $78.9 \%$ of the students of Class 1 were satisfied with the SPOC teaching mode. A total of $76.3 \%$ of the students believed they could master key knowledge and understand text content well. A total of $84.2 \%$ of the students stated that the classroom interaction among students and between students and the teacher was good and the classroom atmosphere was active. A total of $81.6 \%$ students increased their English learning interest, and 92.1\% students increased their independent learning continuously throughout the curriculum period.

Compared with Class 1 , only $52.6 \%$ of the students from Class 2 were satisfied with the traditional teaching mode. A total of $60.5 \%$ of the students believed they could master key knowledge points. However, most students in Class 2 agreed that the traditional teaching mode did not stimulate classroom interaction, and students had difficulty increasing their learning interests as well as their independent learning.

Contrastive analysis proved that students in the SPOC teaching mode achieved high quality learning than students in the traditional teaching mode under the same cognition background. 


\subsection{After-class evaluation and opinions}

After class and at the end of the semester, students could evaluate the SPOC and traditional teaching modes. They could also provide improvement suggestions on the teaching platform or comment book. Some responses are listed in Table 5. The students preferred the SPOC teaching mode more than the traditional teaching mode. Most participants in the SPOC teaching model agreed that it was a positive learning mode. Most students provided remarkable evaluations about online learning before the class and the interaction during and after class.

Table 5. Evaluation and opinions

\begin{tabular}{|l|l|}
\hline & \multicolumn{1}{|c|}{ Evaluation and opinions } \\
\hline SPOC teaching mode & $\begin{array}{l}\text { Message 1: Knowledge points are easy to understand. Difficulties are ad- } \\
\text { dressed thoroughly, and interactions increased. The central idea of the text } \\
\text { can be understood from different aspects. } \\
\text { Message 2: The teacher exerts great effort in the course, and the curriculum } \\
\text { classification is very good. The online module is easy to use and was ex- } \\
\text { plained comprehensively. Classroom teaching can deepen explanation of } \\
\text { difficulties, which helps students understand the text connotation fundamen- } \\
\text { tally. } \\
\text { Message 3: The video speed is appropriate. Students will not miss the content } \\
\text { because of speed problems. This classroom teaching method is very interest- } \\
\text { ing, and the after-class group activities are very interesting. }\end{array}$ \\
\hline Traditional teaching mode & $\begin{array}{l}\text { Message 1: The teacher has processed the text carefully. The structural } \\
\text { analysis and interpretation of key knowledge points are remarkable. However, } \\
\text { comments about homework and classroom discussion are brief. } \\
\text { Message 2: I hoped to further stimulate the classroom atmosphere. } \\
\text { Message 3: The teacher has explained the text thoroughly, but I think that } \\
\text { understanding the cultural background deeply is difficult. The curriculum is } \\
\text { generally boring. }\end{array}$ \\
\hline
\end{tabular}

\section{Conclusion}

This study aims to perfect the current teaching mode and offset the shortcomings of the traditional teaching mode by combining information technology and traditional teaching. The features and advantages of the SPOC teaching mode were discussed, and the construction method of SPOC teaching mode was elaborated. The practical applications of the SPOC teaching mode on "College English" were introduced. Major conclusions can be drawn from data analysis and the questionnaire.

1. The SPOC teaching mode increased the learning interest of the students. Students could arrange learning time and frequency freely before class according to their own situations. Learning became convenient, flexible, and individualized. Students could change from passive learning to positive learning, and their ability to master knowledge was strengthened.

2. The many group discussions and debate opportunities that created a fair interactive teaching environment for the teacher and students were arranged during and after class. Students could express opinions during discussions and strengthen their un- 
derstanding of the material. In addition, students had opportunities to present themselves, increase their confidence, and stimulate their learning motivation.

3. The SPOC platform not only provided rich teaching resources but also increased interest in the teaching process. The teacher could mix with students and provide instruction according to their learning situations. Students became active in understanding knowledge points, expanding their scope of knowledge, and strengthening independent learning and ability to analyze and solve problems.

The SPOC teaching mode based on MOOCs integrates the traditional teaching mode and technology. SPOCs improve the teaching effect, increase students' learning interest, and change students from passive learners into positive knowledge explorers. However, the SPOC teaching mode is imperfect. Students and teachers still have to spend a great amount of time in preparation before the class. Fragmented time and systemized teaching are contradicting. Students also have to pay attention to balancing their learning. The SPOC teaching mode is a development of MOOCs. This SPOC was used on a university campus to increase students' independent learning and innovation abilities. However, the teachers still have to improve its promotion of teaching activities and specific implementation methods.

\section{$7 \quad$ Acknowledgment}

This study was supported by the National Natural Science Foundation of China (61502037).

\section{References}

[1] He Bin, Cao Yang. SPOC: MOOC-based Innovation of Teaching Processes, China Educational Technology, 2015, Vol. 3(338), pp.22-29.

[2] Hashmi, AH. HarvardX Set To Launch Second SPOC (May 2018), retrieved from http://harvardx.harvard.edu/links/harvardx-set-launch-second-spocharvard-crimson-amnah-hashmi-september-16-2013.

[3] Salman Han. The One World Schoolhouse: Education Reimagined, Twelve, 2013, pp.5258

[4] Ma Xiulin, Mao He, Wang Cuixia. From MOOC to SPOC: An Empirical Study on the Effect of Two Kinds of Online Learning Modes, Journal of Distance Education, 2016, Vol. 4(006), pp. 43-51.

[5] Gu Xiaoqing, Feng Yuanyuan, Sichang Hu. Go beyond the Fragmentation: Semantic Diagram and Deep Learning. China Educational Technology, 2015, Vol. 3(338), pp. 39-48.

[6] Fox, A., David, A. Patterson. Software Engineering Curriculum Technology Transfer: Lessonslearned from MOOCs and SPOCs (June 2018), retrieved from https://www2.eecs.berkeley.edu/Pubs/TechRpts/2014/EECS-2014-17.pdf.

[7] Xu Wei, Jia Yongzheng, Fox, A., Patterson, D. From MOOC to SPOC: Lessons from MOOC at Tsinghua and UC Berkeley. China Academic Journal Electronic Publish House, 2014, vol. (4), pp.13-22. 
[8] Goral, T., Make Way for SPOCS:Small,Private Online Courses May Provide What MOOCs Can't. (June 2018), retrieved from https://www.questia.com/magazine/1G1337618040/make-way-for-spocs-small-private-online-courses.

[9] Hoffmann, R. MOOCs-Best Practices and Worst Challenges (October 10). MOOCs-Best Practices and Worst Challenges. In Making Sense of the MOOCs, Paper presented at the meeting of Academic Cooperation Association (ACA), Brussels. (June 2018), retrieved from http://www.aca-secretariat.be/index.php?id=675\#c2893.

[10] Kang Yeqin, An Analysis on SPOC: Post-MOOC Era of Online Education. China Academic Journal Electronic Publish House, 2014, vol. 35(1), pp.85-93.

[11] McAuley, A., Stewart, B., Siemens G., Cormier, D. The MOOC Model for Digital Practice, University of Prince Edward Island, Social Sciences and Humantities Research Council's Knowledge Synthesis Grants on the Digital Economy (2010), (June 2018), retrieved from http://www.elearnspace.org/Articles/MOOC Final.pdf

[12] The New York Times, The Year of the MOOC (June 2018), retrieved from https://wenku.baidu.com/view/e4b944dda8956bec0975e3e5.html.

[13] ICEF Monitor, Are we really enter into post-Mooc era? (June 2018), retrieved from $\mathrm{http}: / /$ monitor.icef.com/2013/11/are-we-already-entering-a-post-mooc-era/.

[14] Combéfis, S., Bibal, A., Peter Van Roy. Recasting a Traditional Course into a MOOC by Means of a SPOC, European MOOCs Stakeholders Summit 2014, (June 2018), retrieved from https://www.mendeley.com/research-papers/recasting-traditional-course-moocmeans-spocno-title/.

[15] Xu Xiaoshu, Chen Huimin. Recasting English for Environmental Science into a SPOC-A Pilot Study in Wenzhou University (June 2018), retrieved from https://link.springer.com/ chapter/10.1007/978-3-662-47490-7 21

\section{Authors}

Zhe Kang is a lecturer in the Information Technology Centre of BFSU, Beijing Foreign Studies University, Beijing 100089, China (kangzhe@bfsu.edu.cn).

Le He is with Université du Québec à Trois-Rivières, Trois-Rivières, Canada (perol@sina.com).

Article submitted 12 October 2018. Resubmitted 15 November 2018. Final acceptance 23 November 2018 Final version published as submitted by the authors. 